\title{
Shortwave direct radiative forcing of Saharan dust aerosols over the Atlantic Ocean
}

\author{
XIONG LIU, JUN WANG and SUNDAR A. CHRISTOPHER* \\ Department of Atmospheric Sciences, University of Alabama in Huntsville, \\ Huntsville, Alabama 35805, USA
}

(Received 22 November 2001; in final form 7 February 2003)

\begin{abstract}
Using collocated Visible and Infrared Scanner (VIRS) and Clouds and the Earth's Radiant Energy Budget Scanner (CERES) data on board the Tropical Rainfall Measuring Mission (TRMM) satellite, the instantaneous Shortwave Aerosol Radiative Forcing (SWARF) and daytime diurnally averaged SWARF at the top-of-atmosphere (TOA) are estimated for Saharan dust over the Atlantic Ocean $\left(10^{\circ} \mathrm{N}-25^{\circ} \mathrm{N}, 30^{\circ} \mathrm{W}-15^{\circ} \mathrm{W}\right)$ for July 1998 . A combination of reflectance thresholds, along with infrared spatial coherence techniques, are used to separate dust aerosols from clouds. Using Mie and Discrete Ordinate Radiative Transfer (DISORT) calculations and the VIRS channel 1 reflectance, dust optical thickness $(\tau)$ is retrieved. The average instantaneous direct SWARF of dust aerosols per unit $\tau$ is $-50 \mathrm{~W} \mathrm{~m}^{-2}$. The daytime diurnally averaged SWARF of dust aerosols is $-15.2 \pm 10.9 \mathrm{~W} \mathrm{~m}^{-2}$ for a mean $\tau$ of $0.79 \pm 0.39$. This study demonstrates that the synergistic use of instruments from different parts of the electromagnetic spectrum can be used to study the radiative effects of dust aerosols. This study is also among the first to estimate the diurnal SWARF of dust aerosols using satellite sensor data.
\end{abstract}

\section{Introduction}

The Sahara is a major source of dust aerosols (Prospero 1990) and the dust transport from the Sahara is an important climatic process (Tegen and Lacis 1996, Hansen et al. 1997, Coakley and Cess 1985, Moulin et al. 1997). The aerosols reflect the incoming solar radiation to space, thereby reducing the amount of sunlight available to the ground. This is called the 'direct' radiative effect of aerosols. The aerosols also serve as cloud condensation nuclei and change the cloud albedo and microphysical properties of clouds, which is called the 'indirect' radiative effect. The effect of aerosols is comparable in magnitude but opposite in sign to that of the greenhouse effect (IPCC 1995). While the effect of aerosols is to reduce the surface temperature, the increase in greenhouse gases increases the surface temperature (Hansen et al. 1997). The magnitude of the global mean radiative forcing of dust aerosols is comparable to that of anthropogenic aerosols from sulphate and biomass combustion (IPCC 1994, Sokolik and Toon 1996). There are considerable

\footnotetext{
*Corresponding author; e-mail: sundar@nsstc.uah.edu

International Journal of Remote Sensing

ISSN 0143-1161 print/ISSN 1366-5901 online (C) 2003 Taylor \& Francis Ltd

http://www.tandf.co.uk/journals

DOI: $10.1080 / 0143116031000114824$
} 
uncertainties in estimating the radiative effects of dust aerosols. The net radiative forcing at the top-of-atmosphere (TOA) could be either positive or negative, depending on several key variables such as surface albedo, particle size, vertical distribution of the dust layer, dust optical depth $(\tau)$, and the imaginary part of the refractive index (Tegen and Lacis 1996, Liao and Seinfeld 1998).

To study the global radiative effects of dust aerosols, routine global observations from satellites are necessary. The global and temporal distribution of dust aerosols and their sources and sinks must be well characterized. A variety of methods have been developed to track dust outbreaks and infer dust mass loading (e.g. Ackerman 1997, Herman et al. 1997, Kaufman et al. 2000). The detection of aerosols using visible imagery is most successful over ocean due to the dark ocean background (Stowe et al. 1997, Ignatov and Stowe 2000). Over desert areas, this method is limited due to the brighter surface. Satellite remote sensing of dust can also be conducted using thermal infrared (Ackerman 1989, Tanré and Legrand 1991, Ackerman 1997, Wald et al. 1998) or the ultraviolet part of the electromagnetic spectrum (Hsu et al. 1996). However, there are limitations to these methods. The thermal techniques are dependent on the scene and atmospheric temperatures and the UV methods are not sensitive to the dust in the lowest $1-2 \mathrm{~km}$ (Herman et al. 1997).

In addition to the dust detection and $\tau$ retrieval using narrowband measurements (e.g. from the Advanced Very High Resolution Radiometer; AVHRR), broadband measurements (e.g. from the Clouds and the Earth's Radiant Energy System, CERES) are necessary for accurately evaluating the radiative effects of aerosols. Ackerman and Chung (1992) studied the radiative effects of dust using the Earth Radiation Energy Budget (ERBE) data for selected days, although no $\tau$ retrievals were performed. Christopher et al. (2000) used collocated Visible and Infrared Scanner (VIRS) and CERES data from the Tropical Rainfall Measuring Mission (TRMM) satellite and quantified the instantaneous Shortwave Aerosol Radiative Forcing (SWARF) of smoke aerosols as a function of $\tau$. The precessing orbit of TRMM (Kummerow et al. 1998) allows for several measurements at the same location in a single day, thereby improving the temporal sampling to obtain the diurnally averaged forcing of clouds or aerosols. Recently, Hsu et al. (2000) used the TOMS and ERBE data to study the radiative effects of dust aerosols. However, since the TOMS and ERBE instruments are on different satellites, precise temporally matching of datasets is a problem.

The focus of this paper is to detect Saharan dust aerosols using VIRS imagery and to estimate $\tau$ over the Atlantic Ocean. A sensitivity analysis is conducted to examine the effect of assumed aerosol properties on $\tau$ retrievals. The instantaneous and diurnally averaged SWARF are then estimated from CERES data. This is among the first studies to examine the daytime diurnal variation of dust aerosols using satellite sensor data.

\section{Data}

The VIRS and CERES on the TRMM satellite are used. The VIRS is used to detect dust aerosols and estimate $\tau$ and the CERES is used to estimate the radiative effects of dust aerosols.

The VIRS is a five-channel scanning radiometer that measures the solar reflected and Earth-emitted radiation from the Earth-atmosphere system from a $350 \mathrm{~km}$ 
precessing orbit with a nadir resolution of $2.1 \mathrm{~km}$ (Kummerow et al. 1998). The five channels are centred at $0.63,1.6,3.75,10.8$ and $12.0 \mu \mathrm{m}$, respectively. The reflected and emitted portions of the VIRS $3.75 \mu \mathrm{m}$ channel are separated following the procedures outlined by Kaufman and Nakajima (1993).

The CERES is a broadband instrument that measures radiances at TOA in three bands $(0.3$ to $>50 \mu \mathrm{m}, 0.3-5 \mu \mathrm{m}$ and $8-12 \mu \mathrm{m})$ at a spatial resolution of about $10 \mathrm{~km}$ at nadir (Wielicki et al. 1996). In this study, we used the ERBE-like instantaneous TOA estimates, which converts the CERES-measured radiances using the ERBE shortwave angular distribution models (Wielicki and Green 1989).

Twenty-five collocated VIRS and CERES images were used in this study from 2 to 18 July 1998 (table 1 ). The region of study is between $10^{\circ} \mathrm{N}-25^{\circ} \mathrm{N}$ and $15^{\circ} \mathrm{W}-$ $30^{\circ} \mathrm{W}$.

\section{Methodology and results}

\subsection{Identifying dust in VIRS imagery}

Figure 1(a) shows a radiometrically enhanced pseudo colour-composite VIRS imagery over the Atlantic Ocean, in which channel 1, 2 and 3 (reflected part) are associated with red, green and blue colours, respectively. The blurring effect of dust is seen in the middle and lower part of this image. To study the radiative effects of dust aerosols, we must first remove clouds from VIRS imagery. The spatial coherence method (Coakley and Bretherton 1982) and a visible reflectance threshold

Table 1. Twenty-five collocated VIRS and CERES images used in this study from 2 to 18 July 1998.

\begin{tabular}{llrcr}
\hline Image & Date & $\begin{array}{c}\text { Latitude range } \\
\left({ }^{\circ} \mathrm{N}\right)\end{array}$ & $\begin{array}{c}\text { Longitude range } \\
\left({ }^{\circ} \mathrm{W}\right)\end{array}$ & GMT Time \\
\hline 1 & $2.5-14.2$ & $26.8-14.5$ & $8: 54$ \\
2 & 2 July & $17.9-26.9$ & $26.7-17.1$ & $10: 30$ \\
3 & 2 July & $11.8-21.5$ & $26.8-16.6$ & $9: 18$ \\
4 & 3 July & $15.1-24.5$ & $26.6-16.5$ & $17: 24$ \\
5 & 3 July & $19.8-27.9$ & $22.9-15.0$ & $16: 12$ \\
6 & 4 July & $2.4-16.4$ & $26.7-11.1$ & $17: 48$ \\
7 & 4 July & $13.7-23.5$ & $26.7-16.1$ & $8: 30$ \\
8 & 5 July & $13.0-22.8$ & $26.6-16.1$ & $16: 36$ \\
9 & 5 July & $18.7-27.9$ & $25.8-15.7$ & $15: 24$ \\
10 & 6 July & $2.5-14.4$ & $26.7-14.1$ & $17: 00$ \\
11 & 6 July & $11.4-21.1$ & $26.6-16.4$ & $15: 48$ \\
12 & 7 July & $17.5-26.8$ & $26.5-16.4$ & $14: 36$ \\
13 & 8 July & $9.7-19.2$ & $26.7-17.0$ & $13: 00$ \\
14 & 9 July & $16.1-25.1$ & $26.6-17.1$ & $12: 30$ \\
15 & 10 July & $20.3-27.9$ & $21.7-15.0$ & $14: 06$ \\
16 & 11 July & $5.2-17.1$ & $26.7-13.8$ & $12: 54$ \\
17 & 11 July & $14.1-23.5$ & $26.6-16.8$ & $11: 42$ \\
18 & 12 July & $19.0-27.9$ & $24.7-15.3$ & $13: 18$ \\
19 & 13 July & $2.4-15.1$ & $26.7-13.0$ & $12: 06$ \\
20 & 13 July & $12.0-21.8$ & $26.6-16.3$ & $10: 54$ \\
21 & 14 July & $17.9-27.3$ & $26.5-16.1$ & $12: 30$ \\
22 & 15 July & $2.5-13.1$ & $26.8-15.9$ & $11: 18$ \\
23 & 15 July & $10.4-16.8$ & $26.7-16.8$ & $10: 06$ \\
24 & 16 July & $17.0-25.8$ & $26.5-17.4$ & $10: 30$ \\
25 & 17 July & $9.6-18.0$ & $26.7-18.8$ & \\
\hline
\end{tabular}


(a)

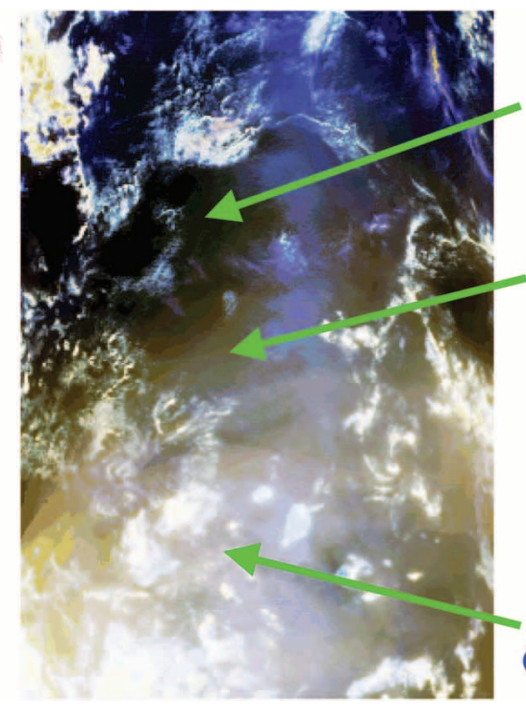

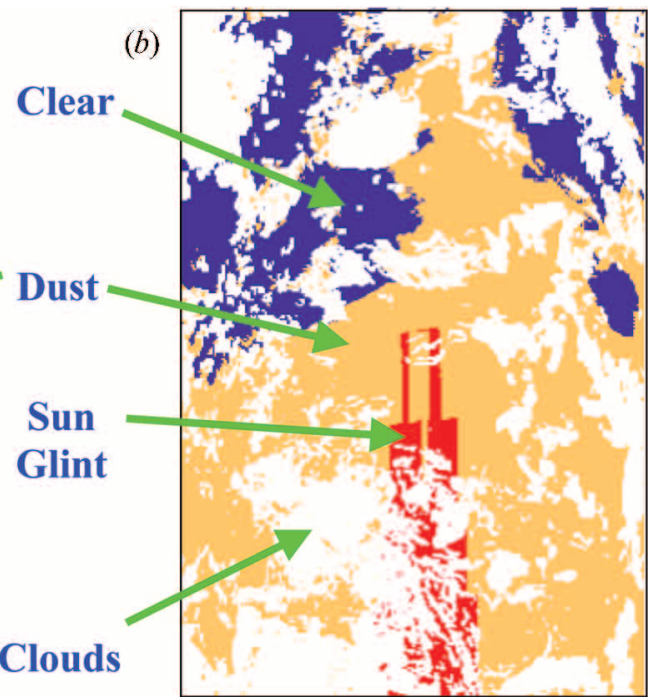

Figure 1. A VIRS image over the Atlantic Ocean on 9 July 1998. (a) Three-band overlay colour composite image (channel 1 red, channel 2 green, reflected portion of channel 3 blue). (b) The same image after classification, in which white means clouds, red means sun glint, blue means clear sky, and yellow means dust. A 50\% relative probability cut-off is used to identify sun-glint.

method were used to detect clouds. In the spatial coherence method, the thresholds of mean temperature and standard deviation are identified by examining the scatter-plot of standard deviation versus mean channel 4 temperature in a $3-$ pixel $\times 3$-pixel template. If the mean temperature of the $3 \times 3$ array of pixels is less than $285 \mathrm{~K}$ or if the standard deviation is greater than $0.2 \mathrm{~K}$, or if the channel 1 reflectance is greater than $25 \%$, then it is classified as cloudy. Sun glint occurs when the incident light is reflected directly from the surface of the water to the satellite sensor. To exclude the effects of sun glint, the high-probability (greater than $50 \%$ ) sun glint pixels were masked, based on the viewing geometry of the measurements (Berendes et al. 1999). To obtain the radiative forcing of dust aerosols, clear-sky pixels must be detected because radiative forcing is defined as the difference between clear and aerosol conditions (Christopher et al. 2000). The term 'clear-sky pixels' is used to denote pixels that are not contaminated by dust aerosols and clouds. If the channel 1 reflectance is lower than $6 \%$ and the ratio of channel 2 to channel 1 is less than 0.7 , we classify it as a clear-sky pixel. Visible channels from satellite imagery are effective in detecting aerosols over oceans (Rao et al. 1989, Ackerman and Chung 1992, Ignatov and Stowe 2000). The existence of dust over ocean can enhance the reflectance as seen in figure $1(a)$. The classified image of figure $1(a)$ is shown in figure $1(b)$. Clouds are well separated from dust in this image. However, some pixels at cloud edges could also be identified as dusty pixels.

We classified all the VIRS images during 6-18 July 1998 in the region between $10^{\circ} \mathrm{N}-25^{\circ} \mathrm{N}$ and $30^{\circ} \mathrm{W}-15^{\circ} \mathrm{W}$, using the methodology described above. The overall coverage of clear, cloudy, sun glint, and dust are 5.0\%, 76.2\%, 2.2\% and $21.2 \%$, respectively. Some dust pixels are mixed together with cloudy pixels, which might 
indirectly change the optical properties and radiative effects of clouds. However, this indirect effect of aerosols is not the focus of this study.

The spectral differences between dust and clear sky is most evident in visible channels. The average reflectance of dust is $4-6 \%$ higher than that of clear sky. The infrared channels are also useful in detecting dust, especially over land. Ackerman (1997) showed that the brightness temperature (BT) difference between 11 and $12 \mu \mathrm{m}$ channels $\left(T_{45}\right)$ for dust over desert is negative because dust has higher emissivity at $12 \mu \mathrm{m}$ than at $11 \mu \mathrm{m}$. In this study, the average $T_{45}$ for clear sky is about $2.1 \mathrm{~K}$. The $T_{45}$ values are usually larger at lower latitudes, because there is usually more water vapour in tropical areas. For dust pixels, the average $T_{45}$, channel 3 and channel $4 \mathrm{BT}$ differences $\left(T_{34}\right)$ are $1.1 \mathrm{~K}$ and $8.1 \mathrm{~K}$, respectively. Since these BT differences are usually dependent on water vapour amount, we cannot use fixed thresholds to separate clear-sky pixels from dust pixels. However, the $T_{45}$ value of dust is usually smaller than that of clear sky and the $T_{34}$ values are usually larger than that of clear sky.

\subsection{Dust optical thickness retrieval}

A look-up table approach is used to retrieve $\tau$ that is similar to the one used in Christopher et al. (2000). Mie calculations and a Discrete Ordinate Radiative Transfer (DISORT) model (Ricchiazzi et al. 1998) are used to build the look-up table. Although dust aerosols are not spherical (Wiscombe and Mugnai 1988, Michchenko et al. 1995), it is difficult to obtain information about particle shape parameters. Therefore, Mie calculations are used in current dust aerosol optical property retrieval from satellite measurements (e.g. Tanré et al. 1997, Kaufman et al. 1997, 2000, 2001). Mie calculations require the real $\left(n_{\mathrm{r}}\right)$ and imaginary part of refractive index $\left(n_{\mathrm{i}}\right)$ and aerosol size distribution. The complex refractive index of a particle depends on the chemical composition. The $n_{\mathrm{r}}$ values for dust ranges from 1.5 to 1.55 (Moulin et al. 1997). However, the $n_{\mathrm{i}}$ values are variable, ranging from 0.001 to 0.012 at about $0.63 \mu \mathrm{m}$ (Moulin et al. 1997). We used the complex refractive index of dust from Kaufman et al. (2000). The assumed $n_{\mathrm{r}}$ is 1.53 and $n_{\mathrm{i}}$ is 0.001 . The size distribution of dust aerosols is assumed log-normal, with an effective radius $\left(R_{\mathrm{e}}\right)$ of $2 \mu \mathrm{m}$ and a logarithmic standard deviation of $0.8 \mu \mathrm{m}$. The calculated single scattering albedo $(\omega)$ at $0.66 \mu \mathrm{m}$ is 0.97 and asymmetry factor $(g)$ is 0.72 . To analyse the sensitivity of dust optical thickness retrieval to $n_{\mathrm{i}}$ and particle size, we calculated the optical properties while changing $n_{\mathrm{i}}$ to 0.002 and 0.003 or changing the effective radius $\left(R_{\mathrm{e}}\right)$ to 1 and $3 \mu \mathrm{m}$ (see table 2 ). The single scattering albedo is more sensitive to $n_{\mathrm{i}}$, and $g$ and extinction efficient are more sensitive to $R_{\mathrm{e}}$.

The calculated optical properties listed in table 2 and the phase function serve as

Table 2. Dust optical properties calculated from Mie Code $(\omega$, single scattering albedo; $g$, asymmetry factor; $\beta$, extinction coefficient) at a wavelength of $0.63 \mu \mathrm{m}$ for different effective radii $\left(R_{\mathrm{e}}\right)$ and imaginary part of reflective index $\left(n_{\mathrm{i}}\right)$.

\begin{tabular}{llllll}
\hline$R_{\mathrm{e}}(\mu \mathrm{m})$ & 2 & 2 & 2 & 1 & 3 \\
$n_{\mathrm{i}}$ & 0.001 & 0.002 & 0.003 & 0.001 & 0.001 \\
\hline$\omega$ & 0.966 & 0.938 & 0.913 & 0.983 & 0.954 \\
$g$ & 0.721 & 0.728 & 0.735 & 0.686 & 0.747 \\
$\beta\left(\mathrm{m}^{-1}\right)$ & 0.0044 & 0.0044 & 0.0044 & 0.0012 & 0.0096 \\
\hline
\end{tabular}


input to the DISORT model. The average clear-sky TOA reflectance from VIRS data is about $4.9 \%$. Accounting for atmospheric effects, the ocean surface reflectance is about $3 \%$. Since the region of interest is mainly located northward of $10^{\circ} \mathrm{N}$, the mid-latitude summer atmospheric profiles are used with a water vapour amount of $2.9 \mathrm{~g} \mathrm{~cm}^{-2}$ (McClatchey et al. 1971). In the look-up tables, the radiance is calculated for solar zenith angles ranging from $0^{\circ}$ to $75^{\circ}$ in $3^{\circ}$ increments, view zenith angles from $0^{\circ}$ to $48^{\circ}$ in $3^{\circ}$ increments, and azimuth angles from $0^{\circ}$ to $180^{\circ}$ for $20^{\circ}$ increments. For the sensitivity studies, surface reflectance is varied from $2 \%$ to $4 \%$ and tropical atmospheric profiles are tested against the mid-latitude profiles.

With these input parameters, the VIRS channel 1 reflectance at the TOA is calculated as a function of $\tau$ for different conditions. Sensitivity analysis is performed by varying the input parameters as shown in figure 2 . For smaller $\tau$, the channel 1 reflectance is most sensitive to surface reflectance but this sensitivity decreases rapidly for larger $\tau$ values. For example, when $\tau$ is 0.25 , a change in surface reflectance from 0.03 to 0.04 will increase the TOA reflectance by about $1 \%$. Therefore, if surface reflectance is assumed to be 0.03 instead of 0.04 , the retrieved dust $\tau$ will increase to 0.4 in the above example. For $\tau$ values larger than 0.5 , the channel 1 reflectance is very sensitive to the $R_{\mathrm{e}}$ and the $n_{\mathrm{i}}$. For example, when $\tau$ is 1.0 , the channel 1 TOA reflectance increases from 0.12 to 0.14 as $R_{\mathrm{e}}$ increases from $2 \mu \mathrm{m}$ to $3 \mu \mathrm{m}$, and decreases from 0.12 to 0.11 as $n_{\mathrm{i}}$ changes from 0.001 to 0.002 . The decrease of $R_{\mathrm{e}}$ increases the reflectance and vice versa. The increase of $n_{\mathrm{i}}$ (i.e. increases dust absorption) decreases the reflectance. The retrieved average $\tau$ for

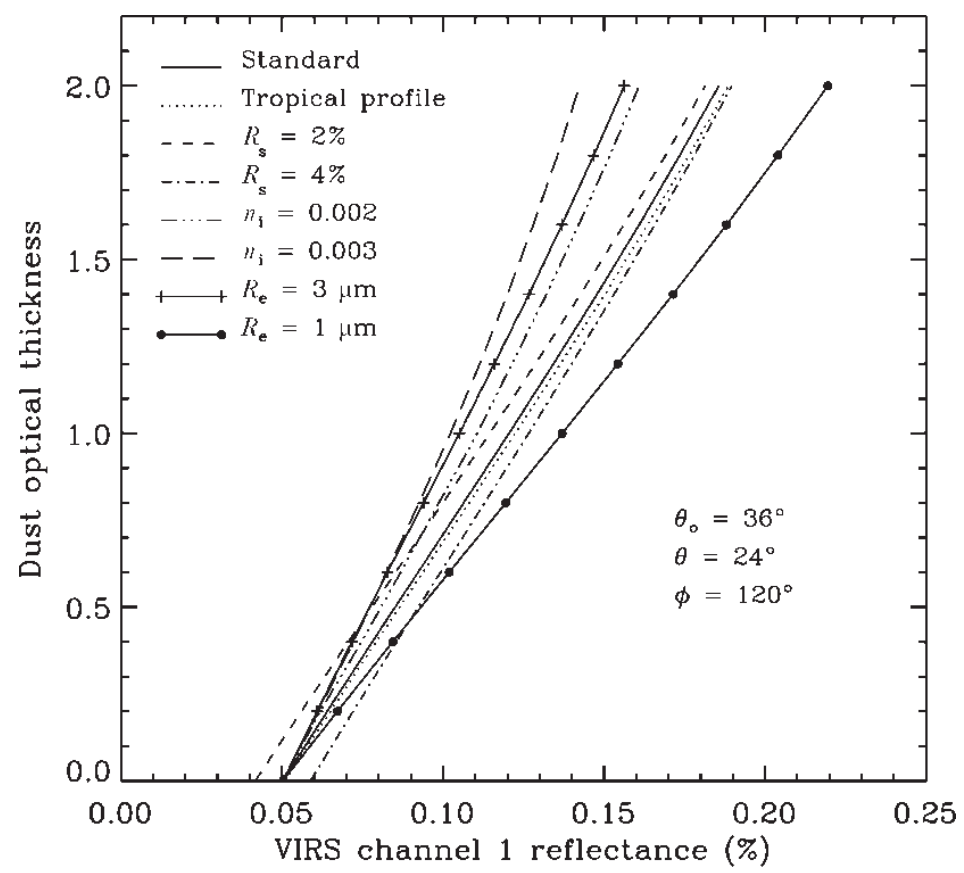

Figure 2. Sensitivity of dust aerosol optical thickness retrieval to refractive index, effective radius, surface reflectance, and water vapour profiles. For the standard case, the complex refractive index is $1.53-0.001 i$, the effective radius is $2 \mu \mathrm{m}$, and the surface reflectance is $3 \%$. Mid-latitude summer atmospheric profiles are used. 
Table 3. Average optical thickness ( \pm 1 standard deviation) at $0.63 \mu \mathrm{m}$ retrieved at different conditions for the image in figure $1 . R_{\mathrm{S}}$ is the surface reflectance, $R_{\mathrm{e}}$ is the effective radius, and $n_{\mathrm{i}}$ is the imaginary part of the refractive index.

\begin{tabular}{lc}
\hline Conditions & Optical thickness \\
\hline Standard case & $0.69 \pm 0.40$ \\
$R_{\mathrm{s}}=2 \%$ & $0.79 \pm 0.40$ \\
$R_{\mathrm{s}}=4 \%$ & $0.59 \pm 0.40$ \\
Tropical & $0.67 \pm 0.39$ \\
$R_{\mathrm{e}}=1 \mu \mathrm{m}$ & $0.57 \pm 0.29$ \\
$R_{\mathrm{e}}=3 \mu \mathrm{m}$ & $0.88 \pm 0.55$ \\
$n_{\mathrm{i}}=0.002$ & $0.82 \pm 0.51$ \\
$n_{\mathrm{i}}=0.003$ & $0.99 \pm 0.73$ \\
\hline
\end{tabular}

figure 1 using the look-up tables in the sensitivity analysis is listed in table 3. The average $\tau$ value is $0.69 \pm 0.4$. The $n_{\mathrm{i}}, R_{\mathrm{e}}$ and surface reflectance are the three key parameters in retrieving dust optical thickness and therefore in studying their radiative effects. The increase of $n_{\mathrm{i}}$ from 0.001 to 0.002 increases the average $\tau$ by 0.13 ; the increase of $R_{\mathrm{e}}$ from $2 \mu \mathrm{m}$ to $3 \mu \mathrm{m}$ increases the average $\tau$ by 0.19 ; the increase of surface reflectance from $3 \%$ to $4 \%$ decreases the average $\tau$ by 0.10 . The use of tropical profiles instead of mid-latitude profiles does not affect the average $\tau$ values, indicating that the selection of atmospheric profiles is not as critical when using the $0.63 \mu \mathrm{m}$ channel reflectance for $\tau$ retrieval. The retrieved average $\tau$ using all the 25 images is $0.84 \pm 0.40$, indicating large dust outbreak events during this period.

\subsection{Dust shortwave radiative forcing}

Since the scene identification types in CERES do not include dust or any other types of aerosols, we need multispectral narrowband measurements, such as VIRS, to first detect aerosols. Figure $3(a)$ and $(b)$ show the VIRS channel 1 image and CERES shortwave flux at exactly the same time and location for 9 July 1998. The dust and cloud features are clearly visible in figure 3. To collocate the VIRS and CERES, all the VIRS pixels, that lie within the CERES footprint, are obtained. If

(a)

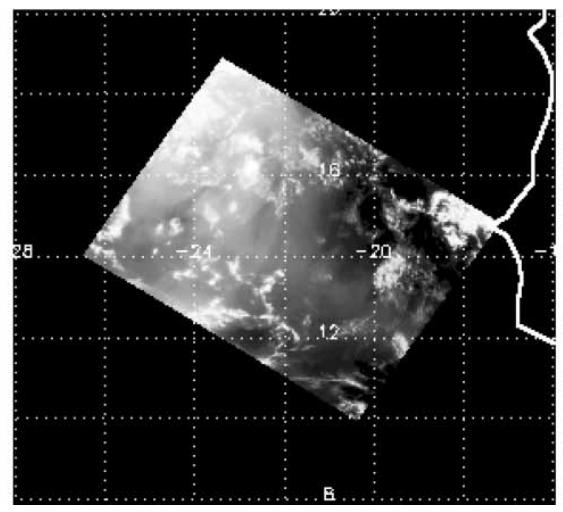

(b)

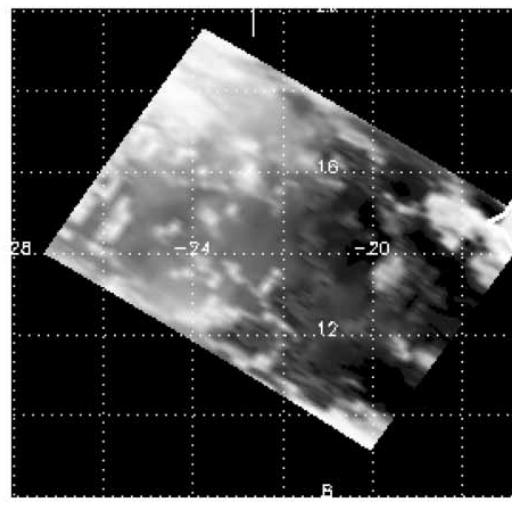

Figure 3. Collocated VIRS and CERES images for 9 July 1998. (a) VIRS channel 1 reflectance image and (b) CERES shortwave flux. 
$90 \%$ of the VIRS pixels are labelled as dust pixels, then the average $\tau$ and the corresponding CERES shortwave flux is obtained for those pixels.

\subsection{Instantaneous Dust Shortwave Forcing (IDSWARF)}

The concept of IDSWARF (Christopher et al. 2000) is the same as cloud shortwave forcing (Ramanathan et al. 1989), and can be defined as:

$$
\operatorname{IDSWARF}=S_{\mathrm{o}} \cos \theta_{\mathrm{o}}\left(\alpha_{\mathrm{clr}}-\alpha_{\text {dust }}\right)
$$

in which the $\theta_{\mathrm{o}}$ is the solar zenith angle; $S_{\mathrm{o}}$ is the incoming solar flux; $\alpha_{\mathrm{clr}}$ and $\alpha_{\text {dust }}$ are the clear-sky albedo and dust-sky albedo at the TOA, respectively. The aerosol SWARF is called instantaneous because they are obtained from satellite images during a specific overpass and time averaging has not been performed. Since we cannot get the clear-sky albedo exactly at the same time and location, we must use clear-sky albedo from other days or other pixels in this image. The clear-sky ocean albedo is a function of $\theta_{\mathrm{o}}$ (Ramanathan et al. 1989). The larger the value of $\theta_{\mathrm{o}}$, the larger the TOA albedo is. Therefore, the clear-sky albedo is actually dependent on the latitude and local solar time. The clear-sky pixels (810 pixels) obtained using 25 images are not enough to constitute a clear-sky albedo map in the region $\left(10^{\circ} \mathrm{N}-\right.$ $\left.25^{\circ} \mathrm{N}, 30^{\circ} \mathrm{W}-15^{\circ} \mathrm{W}\right)$. Instead, a second-order polynomial fit from the available pixels is made as a function of $\theta_{\mathrm{o}}$ :

$$
\alpha_{\mathrm{clr}}=23.6-26.7 \cos \theta_{\mathrm{o}}+9.1 \cos ^{2} \theta_{\mathrm{o}}
$$

The simulated albedo is $6.1 \%$ at $\theta_{\mathrm{o}}$ of $0^{\circ}$ and $19.3 \%$ at $80^{\circ}$. The $\theta_{\mathrm{o}}$ at a given latitude $(\phi)$, date (Julian day, d), and a local solar time $(H)$ is defined (Seinfeld and Pandis 1997) as:

$$
\cos \left(\theta_{\mathrm{o}}\right)=\sin \phi \sin \Delta+\cos \phi \cos \Delta \cos 15^{\circ}(12-H)
$$

where $\Delta$ is the solar inclination angle that can be approximated as (Seinfeld and Pandis 1997):

$$
\Delta \approx \sim-23.27 \cos \frac{2 \pi}{365}(d+10)
$$

Figure 4(a) shows the IDSWARF as a function of $\tau$ for figure 1. There is a very good linear relationship between IDSWARF and $\tau$. A unit $\tau$ amounts to $-50.7 \mathrm{~W} \mathrm{~m}^{-2}$ (by using the slope from figure $4(a)$ ) shortwave forcing (the average $\theta_{\mathrm{o}}$ is about $20^{\circ}$ ). Note that in figure $4(a)$, there are some pixels with large SWARF (magnitude greater than $100 \mathrm{~W} \mathrm{~m}^{-2}$ ). These pixels with large value of SWARF are probably cloudy pixels that were incorrectly classified as dust aerosols. The averaged IDSWARF for this image is $-34.3 \pm 20.4 \mathrm{~W} \mathrm{~m}^{-2}$.

\subsection{Diurnally Averaged Dust Shortwave Forcing (DSWARF)}

Although instantaneous SWARF values are important, we must estimate the diurnal variation of $\tau$ and SWARF. However, it is very difficult to obtain the diurnally averaged forcing directly from polar orbiting (e.g. AVHRR) satellite observations due to the limited temporal sampling. Because the TRMM satellite is in a precessing orbit, several measurements a day over a region are possible. This information could be exploited to estimate the diurnal variation of $\tau$ and SWARF. At a certain region, the $\tau$ could change during the day. In addition, $\theta_{\mathrm{o}}$ changes over time, 


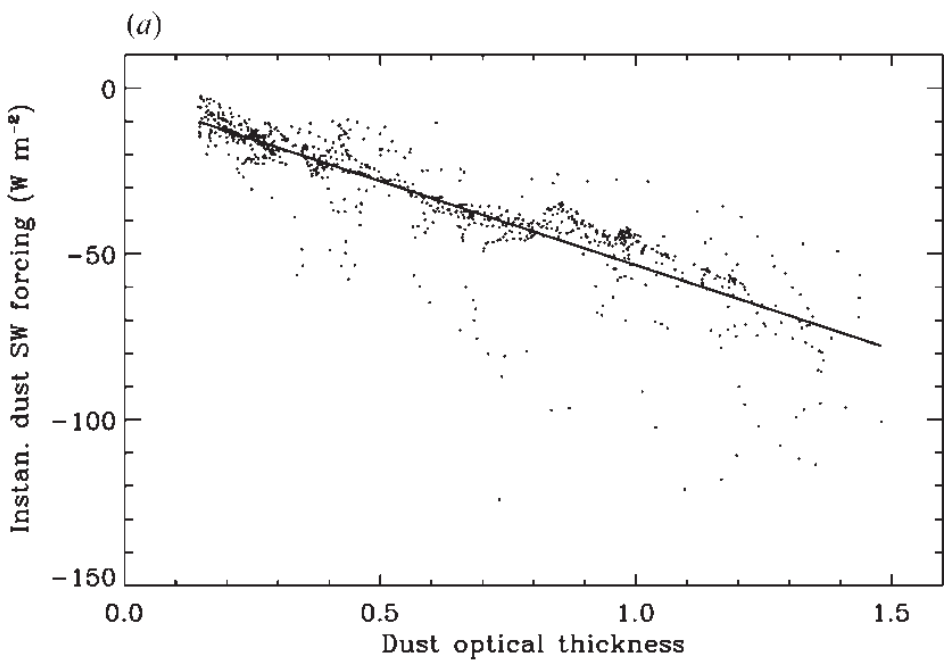

(b)

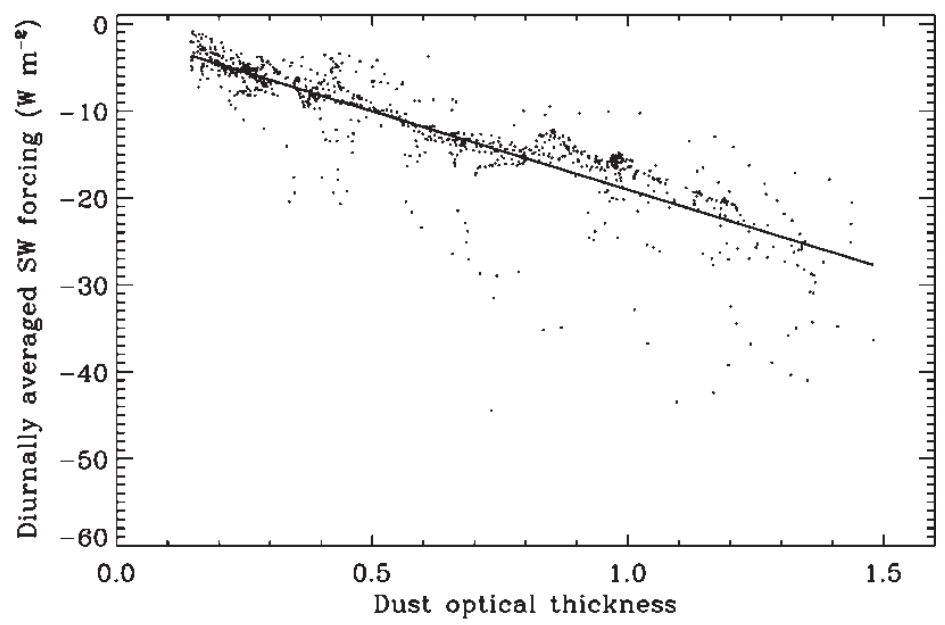

Figure 4. Relationship between dust shortwave forcing and dust optical thickness for figure 1 on 9 July 1998. (a) Instantaneous dust shortwave forcing (the slope and intercept are $-50.68 \mathrm{~W} \mathrm{~m}^{-2}$ and $-2.74 \mathrm{~W} \mathrm{~m}^{-2}$, respectively with a correlation coefficient of -0.87 ). (b) Diurnally averaged dust shortwave forcing (the slope and intercept are $-18.03 \mathrm{~W} \mathrm{~m}^{-2}$ and $-1.03 \mathrm{~W} \mathrm{~m}^{-2}$, respectively with a correlation coefficient of -0.86$)$.

which not only determines the incident solar energy but also affects the $\alpha_{\mathrm{clr}}$ and $\alpha_{\text {dust }}$.

Because the diurnal variation of solar flux is proportional to the cosine of the $\theta_{\mathrm{o}}$, we can model the diurnal variation of $\alpha_{\mathrm{clr}}$ and $\alpha_{\text {dust }}$. Then we can derive the diurnally averaged SWARF using an instantaneous value at anytime by assuming that $\tau$ does not change. If we have several instantaneous values, we can obtain a diurnally averaged SWARF that actually considers the diurnal variation of $\tau, \alpha_{\text {clr }}$ 
and $\alpha_{\text {dust }}$. The diurnally averaged dust shortwave forcing (DSWARF) is defined as:

$$
\operatorname{DSWARF}=\frac{1}{24} \int_{\text {sunrise }}^{\text {sunset }} \operatorname{IDSWARF}(H) \mathrm{d} H
$$

Inserting (1) and (3) into (5), we obtain:

$$
\begin{aligned}
\text { DSWARF }= & \frac{1}{24} S_{\mathrm{o}} \int_{\text {sunrise }}^{\text {sunset }}\left\{\left[\sin \phi \sin \Delta+\cos \phi \cos \Delta \cos 15^{\circ}(12-H)\right]\right. \\
& \times\left(\alpha_{\mathrm{clr}}(H)-\alpha_{\text {dust }}(H)\right) \mathrm{d} H
\end{aligned}
$$

If we assume that $\tau$ does not change over time, and we know how $\alpha_{\text {clr }}$ and $\alpha_{\text {dust }}$ vary with local solar time, then we can derive DSWARF from IDSWARF at any local solar time $H_{i}$ (i.e. we know $\operatorname{IDSWARF}\left(H_{i}\right)$ ):

$$
\begin{aligned}
\text { DSWARF }= & \frac{\frac{1}{24} \int_{\text {sunrise }}^{\text {sunset }}\left\{\left[\sin \phi \sin \Delta+\cos \phi \cos \Delta \cos 15^{\circ}(12-H)\right] \times\left(\alpha_{\text {clr }}(H)-\alpha_{\text {dust }}(H)\right)\right\} \mathrm{d} H}{\left[\sin \phi \sin \Delta+\cos \phi \cos \Delta \cos 15^{\circ}\left(12-H_{i}\right)\right] \times\left(\alpha_{\mathrm{clr}}\left(H_{i}\right)-\alpha_{\text {dust }}\left(H_{i}\right)\right)} \\
& \times \operatorname{IDSWARF}\left(H_{i}\right)
\end{aligned}
$$

If we have several instantaneous values of SWARF at the same location in a day, then $\tau$ could be different for these values. Then we can obtain a diurnally averaged SWARF according to each one of the instantaneous SWARF values. From $n$ values of IDSWARF we can obtain $n$ values of DSWARF. If we average these $n$ values of DSWARF, we can get a diurnally averaged dust SWARF, which considers the diurnal variation of $\tau$ :

$$
\begin{aligned}
\text { DSWARF }= & \frac{1}{n} \sum_{i=1}^{n} \frac{\int_{\text {sunrise }}^{\text {sunset }}\left\{\left[\sin \phi \sin \Delta+\cos \phi \cos \Delta \cos 15^{\circ}(12-H)\right] \times\left(\alpha_{\mathrm{clr}}(H)-\alpha_{\text {dust }}(H)\right)\right\} \mathrm{d} H}{24 \times\left[\sin \phi \sin \Delta+\cos \phi \cos \Delta \cos 15^{\circ}\left(12-H_{i}\right)\right] \times\left(\alpha_{\mathrm{clr}}\left(H_{i}\right)-\alpha_{\text {dust }}\left(H_{i}\right)\right)} \\
& \times \operatorname{IDSWARF}\left(H_{i}\right)
\end{aligned}
$$

To understand how $\alpha_{\mathrm{clr}}$ and $\alpha_{\text {dust }}$ change $\theta_{\mathrm{o}}$, we can use broadband flux models to simulate this variation. For simplification, the difference between $\alpha_{\mathrm{clr}}$ and $\alpha_{\text {dust }}$ is assumed constant. Then equation (8) can be simplified as follows:

$$
\begin{aligned}
\operatorname{DSWARF}= & \frac{1}{n} \sum_{i=1}^{n} \frac{\int_{\text {sunrise }}^{\text {sunset }}\left[\sin \phi \sin \Delta+\cos \phi \cos \Delta \cos 15^{\circ}(12-H)\right] \mathrm{d} H}{24 \times\left[\sin \phi \sin \Delta+\cos \phi \cos \Delta \cos 15^{\circ}\left(12-H_{i}\right)\right]} \\
& \times \operatorname{IDSWARF}\left(H_{i}\right)
\end{aligned}
$$

In this study, we used equation(9) to obtain the diurnally averaged SWARF. Figure 4(b) shows the same DSWARF derived from figure 4 $(a)$. The averaged DSWARF is $-12.3 \pm 7.3 \mathrm{~W} \mathrm{~m}^{-2}$. One unit optical thickness amounts to $18.0 \mathrm{~W} \mathrm{~m}^{-2}$ shortwave forcing.

Using all of the available dust pixels (4832 CERES pixels) during 6-18 July 1998 the IDSWARF and the corresponding DSWARF are derived from equation (9). The average IDSWARF and DSWARF are $-37.9 \pm 27.2 \mathrm{Wm}^{-2}$ and $-15.2 \pm$ $10.9 \mathrm{~W} \mathrm{~m}^{-2}$, respectively, for a mean $\tau$ of $0.79 \pm 0.39$. Both IDSWARF and DSWARF show large spatial variability. The number of dust pixels (CERES) is very small mainly because most of dust pixels are mixed with clouds or sun glint. Therefore, investigation of the interaction between dust and clouds are very important to understand the radiative effects of dust on the global radiation energy budget. To obtain the mean dust shortwave forcing during this period, we average the IDSWARF and DSWARF in $1^{\circ}$ longitude by $1^{\circ}$ latitude areas. The mean 

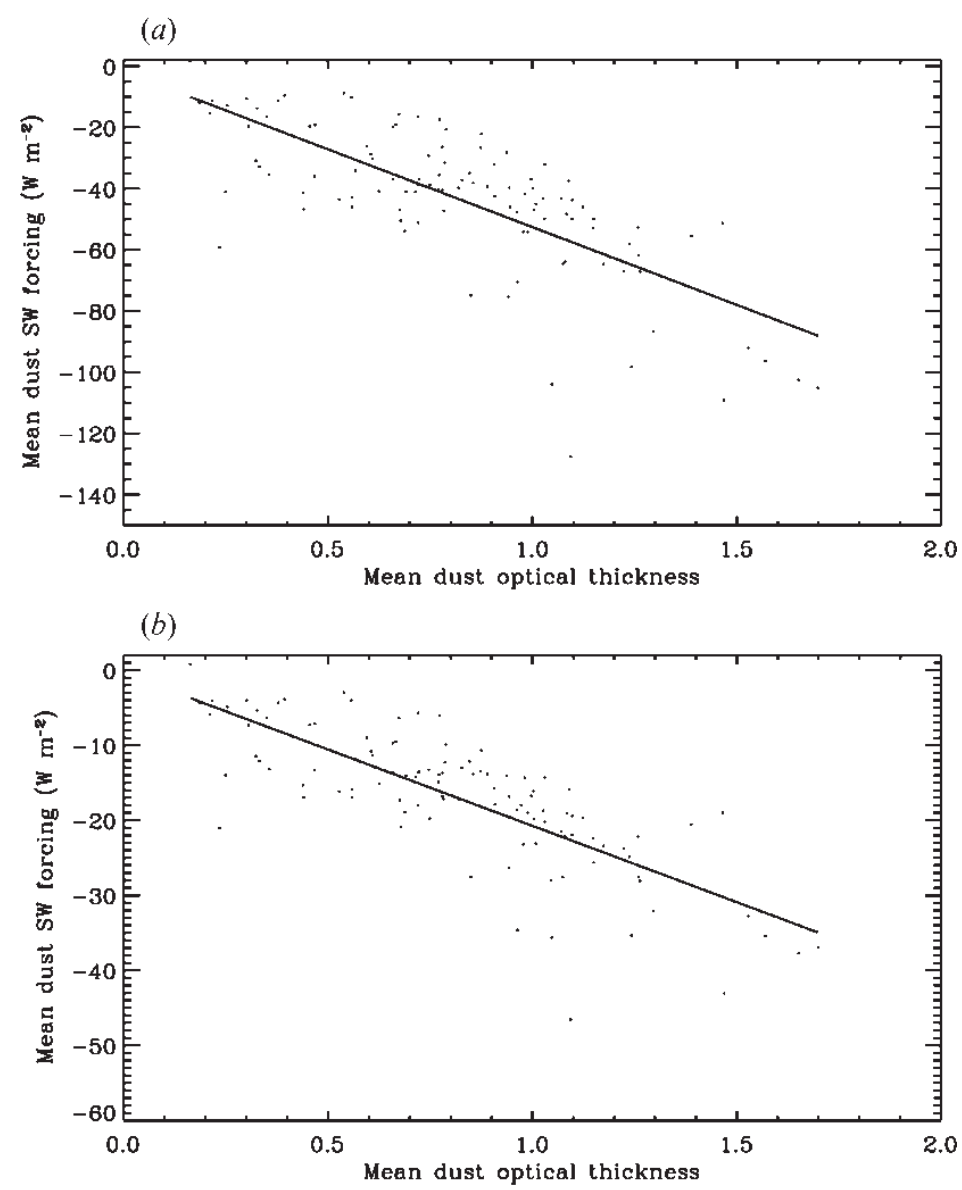

Figure 5. Same as figure 4 except that the data is averaged over a $1^{\circ}$ longitude $\times 1^{\circ}$ latitude area for the entire study period (9-18 July 1998). The slope and intercept are $-50.83 \mathrm{~W} \mathrm{~m}^{-2}$ and $-1.75 \mathrm{~W} \mathrm{~m}^{-2}$, respectively with a correlation coefficient of -0.73 in $(a)$ and $-20.35 \mathrm{~W} \mathrm{~m}^{-2}$ and $-0.38 \mathrm{~W} \mathrm{~m}^{-2}$, respectively with a correlation coefficient of -0.78 in $(b)$.

IDSWARF and DSWARF as a function of $\tau$ are shown in figure 5(a) and $(b)$, respectively. There are good relationships between dust optical thickness and IDSWARF and DSWARF values. A unit optical thickness of dust amounts to $-50.83 \mathrm{~W} \mathrm{~m}^{-2}$ and $-20.4 \mathrm{~W} \mathrm{~m}^{-2}$ for IDSWARF and DSWARF, respectively.

\section{Summary and conclusions}

In this paper, we have examined the radiative effects of dust aerosols using spatially and temporally collocated CERES and VIRS data on board the TRMM satellite over the Atlantic Ocean. This region has frequent dust outbreaks, especially during June through September. Due to the larger radiative effects of clouds, we first mask clouds using spatial coherence methods and reflectance thresholds. Nearly $70 \%$ of the area was covered with clouds, suggesting that it is important to 
investigate the interaction between clouds and dust on radiation energy budget balance.

Mie and DISORT calculations are used to retrieve $\tau$ from the VIRS visible channel measurements. The retrieved $\tau$ during 2-23 July 1998 is $0.84 \pm 0.40$, indicating frequent dust outbreaks during this period. Sensitivity analysis is performed to understand the effects of key parameters such as particle size, $n_{\mathrm{i}}$, surface reflectance, and water vapour profile on $\tau$ retrievals. For low values of $\tau$, the retrieved optical thickness is very sensitive to surface reflectance, but this sensitivity decreases dramatically when $\tau$ increases. For larger $\tau$, the optical thickness is sensitive to the particle size and $n_{\mathrm{i}}$.

Since the clear-sky albedo is a function of solar zenith angle, a second-order polynomial fit is used to simulate this relationship. Then the IDSWARF is simply the product of incoming solar flux and the albedo difference between clear-sky and dust-sky albedo. To obtain diurnally averaged dust shortwave forcing, we derive DSWARF from several instantaneous values by only considering the diurnal variation of the input shortwave flux (i.e. by assuming that the albedo difference between clear sky and dust sky does not change with solar zenith angle). The average diurnally averaged dust shortwave forcing using the images from 6 July to 18 July is $-15.2 \pm 10.9 \mathrm{~W} \mathrm{~m}^{-2}$ for a mean optical thickness of $0.79 \pm 0.39$. One unit optical thickness of dust amounts to $-20.4 \mathrm{~W} \mathrm{~m}^{-2}$. A synergistic use of satellite sensor data from different parts of the electromagnetic spectrum can be used to examine the role of aerosols on regional and global climate.

\section{Acknowledgments}

This research is supported by NASA grants NAGW-5195, NAGW5-7270 and the global aerosol Climatology project. This work is also a part of Xiong Liu's project from the Satellite Remote Sensing Class II (ATS 770) at UAH. We thank Todd Berendes for the VIRS calibration code and Ms Chantae Eatman for her editorial work. The CERES data were obtained from the NASA Earth Observing System Data and Information System, Distributed Active Archive Center (DAAC) at the Langley Research Center, and the VIRS data were obtained through the Goddard Space Flight Center DAAC.

\section{References}

ACKerman, S. A., 1989, Using the radiative temperature difference at 3.7 and $11 \mu \mathrm{m}$ to track dust outbreaks. Remote Sensing of Environment, 27, 129-133.

ACKerman, S. A., 1997, Remote sensing aerosols using satellite infrared observations. Journal of Geophysical Research, 102, 17069-17079.

ACKerman, S. A., and Chung, H., 1992, Radiative effects of airborne dust on regional energy budgets at the top of the atmosphere. Journal of Applied Meteorology, 31, 223-233.

Berendes, T. A., Kuo, K. S., Logar, A. M., Corwin, E. M., Welch, R. M., Baum, B. A., Pretre, A., and Weger, R. C., 1999, A comparison of paired histogram, maximum likelihood, class elimination, and neural network approaches for daylight global cloud classification using AVHRR imagery. Journal of Geophysical Research, 104, 6199-6213.

Christopher, S. A., Chou, J., Zhang, J., Li, X., and Welch, R. M., 2000, Shortwave direct radiative forcing of biomass burning aerosols estimated from VIRS and CERES. Geophysical Research Letters, 27, 2197-2200.

Coakley, J. A., and Bretherton, F. P., 1982, Cloud cover from high-resolution scanner 
data: detecting and allowing for partially filled fields of view. Journal of Geophysical Research, 87, 4917-4932.

COAKley, J. A., JR., and CESS, R. D., 1985, Response of the NCAR community climate model to the radiative forcing by the naturally occurring tropospheric aerosols. Journal of Atmospheric Science, 42, 1677-1692.

Hansen, J., Sato, M., Lacis, A., and Ruedy, R., 1997, The missing climate forcing. Transactions of the Royal Society of London, 352, 231-240.

Herman, J. R., Bhatia, P. K., Torres, O., Hsu, C., Seftor, C., and Celarier, E., 1997, Global distribution of UV-absorbing aerosols from Nimbus 7/TOMS data. Journal of Geophysical Research, 102, 16911-16922.

Hsu, N. C., Herman, J. R., Bhartia, P. K., Seftor, C. J., Torres, O., Thompson, A. M., Gleason, J. F., EcK, T. E., and Holben, B. N., 1996, Detection of biomass burning smoke from TOMS measurements. Geophysical Research Letters, 23, 745-748.

Hsu, N. C., Herman, J. R., and Weaver, C., 2000, Determination of radiative forcing of Saharan dust using combined TOMS and ERBE data. Journal of Geophysical Research, 105, 20649-20662.

Ignatov, A. M., and Stowe, L. L., 2000, Physical basis, premise, and self-consistency of aerosol retrievals from TRMM VIRS. Journal of Applied Meteorology, 39, 2257-2277.

IPCC (InTergovernmental Panel on Climate Change), 1994, Radiative forcing of climate change. In Climate Change 1994, edited by J. T. Houghton, L. G. Meira Filho, J. Bruce, H. Lee, B. A. Callendar, E. Haites, N. Harris and K. Maskell (New York: Cambridge University Press), pp. 131-157.

IPCC (INTER GOVER NMENTAL PANEL ON ClimATE CHANGE), 1995, Climate change. In The Science of Climate Change, edited by J. T. Houghton, L. G. Meira Filho, J. Bruce, H. Lee, B. A. Callendar, E. Haites, N. Harris and K. Maskell (New York: Cambridge University Press), pp. 69-124.

Kaufman, Y. J., and NAKAJima, T., 1993, Effect of Amazon smoke on cloud microphysics and albedo-analysis from satellite imagery. Journal of Applied Meteorology, 32, 729-744.

Kaufman, Y. J., Tanre, D., Remer, L. A., Vermote, E. F., Chu, A., and Holben, B. N., 1997, Operational remote sensing of tropospheric aerosol over land from EOS moderate resolution imaging spectroradiometer. Journal of Geophysical Research, 105, 17051-17076.

Kaufman, Y. J., Karnieli, A., and TANRe, D., 2000, Detection of dust over deserts using satellite data in the solar wavelengths. IEEE Transactions on Geoscience and Remote Sensing, 38, 525-531.

Kaufman, Y. J., Tanre, D., Dubovik, O., Karnieli, A., and Remer, L. A., 2001, Absorption of sunlight by dust as inferred from satellite and ground-based remote sensing. Geophysical Research Letters, 28, 1479-1482.

Kummerow, C., Barnes, W., Kozu, T., Shiue, J., and Simpson, J., 1998, The tropical rainfall measuring mission (TRMM) sensor package. Journal of Atmospheric and Oceanic Technology, 15, 809-817.

LiaO, H., and SEINFELD, J. H., 1998, Radiative forcing by mineral dust aerosols: sensitivity to key variables. Journal of Geophysical Research, 103, 31637-31645.

McClatchey, R. A., Fenn, R. W., Selby, J. E. A., Volz, F. E., and Garing, J. S., 1971, Optical properties of the atmosphere. Report AFCRL-TR-71-0279, Air Force Cambridge Research Laboratory, Bedford, MA.

Michchenko, M. I., Lacis, A. A., Carlson, B. E., and Travis, L. D., 1995, Nonsphericity of dust-like tropospheric aerosols: implications for aerosol remote sensing and climate modeling. Geophysical Research Letters, 22, 1077-1080.

Moulin, C., Dulac, F., Lambert, C. E., Chazette, P., Jankowiak, I., Chatenet, B., and Lavenu, F., 1997, Long-term daily monitoring of Sahara dust load over ocean using Meteosat ISCCP-B2 data: 2 accuracy of the method and validation using sun photometer measurements. Journal of Geophysical Research, 102, 16959-16969.

Prospero, J. M., 1990, Mineral-aerosol transport to the North Atlantic Ocean and North Pacific: the impact of Africa and Asian sources. In The long-range atmospheric 
transport of natural and contaminant substances, edited by A. H. Knap (Norwell, MA: Kluwer Academic), pp. 59-86.

Ramanathan, V., Cess, R. D., Harrison, E. F., Minnis, P., Barkstrom, B. R., Ahmad, E., and HARTMANN, D., 1989, Cloud-radiative forcing and climate: results from the Earth Radiation Budget Experiment. Science, 243, 57-63.

Rao, C. R. N., Stowe, L. L., and McClain, E. P., 1989, Remote sensing of aerosols over the oceans using AVHRR data: theory, practice, and application. International Journal of Remote Sensing, 10, 743-749.

Ricchiazzi, P. J., YANG, S., GAUTIER, C., and Sowle, D., 1998, SBDART: a practical tool for plane-parallel radiative transfer in the Earth's atmosphere. Bulletin of the American Meteorological Society, 79, 2101-2114.

Seinfeld, J. H., and Pandis, A. N., 1997, Atmospheric Chemistry and Physics (New York: John Wiley \& Sons).

SoKolik, I. N., and Toon, O. B., 1996, Direct radiative forcing by anthropogenic mineral aerosols. Nature, 381, 681-683.

Stowe, L. L., Ingatov, A. M., and Singh, R. R., 1997, Development, validation, and potential enhancement to the second-generation operational aerosol product of the National Environmental Satellite, Data, and Information Service of the National Oceanic and Atmospheric Administration. Journal of Geophysical Research, 102, $16923-16934$.

TANRÉ, D., and Legrand, M., 1991, On the satellite retrieval of Sahara dust optical thickness from blurring effects in thematic mapper data. Journal of Geophysical Research, 96, 5221-5227.

Tanré, D., Kaufman, Y. J., Herman, M., and Matto, S., 1997, Remote sensing of aerosol properties over oceans using the MODIS/EOS spectral radiance. Journal of Geophysical Research, 102, 16971-16988.

Tegen, I., and LACIS, A. A., 1996, Modeling of particle size distribution and its influence on the radiative properties of mineral dust aerosol. Journal of Geophysical Research, 101, 19237-19244.

Wald, A., Kaufman, Y. J., Tanré, D., and GaO, B. C., 1998, Daytime and nighttime detection of mineral dust over desert using the thermal IR. Journal of Geophysical Research, 103, 32307-32313.

Wielicki, B. A., and GREen, R. N., 1989, Cloud identification for ERBE radiative flux retrieval. Journal of Applied Meteorology, 28, 1133-1146.

Wielicki, B. A., Barkstrom, B. R., Harrison, E. F., Lee iit, R. B., Smith, G. L., and Cooper, J. E., 1996, Clouds and the Earth's Radiant Energy System (CERES): an earth observing system experiment. Bulletin of the American Meteorological Society, 77, 853-868.

Wiscombe, W. J., and MugnaI, A., 1988, Scattering from non-spherical chebyshev particles 2. Means of angular scattering patterns. Applied Optics, 27, 2405-2421. 